\title{
Adolescents' perceptions about smoking prevention strategies: a comparison of the programmes of the American Lung Association and the Tobacco Institute
}

\author{
Margaret DeBon, Robert C Klesges
}

\begin{abstract}
Objective-To evaluate components of the teenage smoking prevention programmes of the American Lung Association (ALA) and the Tobacco Institute (TI). Design - Group administration of written questionnaires in school. The components of the ALA's and TI's programmes were presented to students in seven strategy vignettes, covering the following topics: peer pressure/enhanced communication; parents as role models; health consequences of smoking; cost of smoking; smoking as an illegal act; tips for quitting smoking; and responsible decision making.
\end{abstract}

Subjects and setting -172 seventh-grade students (mean age $=12.3$ years) from six parochial schools in Memphis, Tennessee, United States.

Main outcome measures-Student ratings of the perceived effectiveness of the ALA and TI approaches (in helping to stop teens from smoking) within each strategy vignette, and students' choice between these two approaches as to which was the better smoking prevention technique.

Results-Although there were some moderating effects of gender and race, participants overall strongly favoured the ALA programme over that of the TI. Of the seven programme components, the ALA's approach was rated more effective on six (peer pressure, parents as role models, the health consequences of smoking, the cost of smoking, tips for quitting smoking, responsible decision making) and the TI's was rated more effective on one (not smoking because it is illegal).

The Universities Prevention Center, Department of Psychology, University of Memphis, Memphis, Tennessee, USA $M$ DeBon

RC Klesges
(Tobacco Control 1996; 5: 19-25)

Keywords: adolescence, smoking prevention
Conclusions-The ALA's program was perceived to be much more effective whom these programmes are ultimately intended to influence-young people. Future research in this area should pursue longitudinal designs to determine if programme endorsement is predictive of smoking status.

\section{Introduction}

More than 3000 teenagers in the United States become regular smokers each day and nearly. half of all adult smokers start smoking regu- $\overrightarrow{0}$ larly before the age of $18 .^{1}$ In addition, if appears that young people are starting to smoke at earlier ages. Tobacco use begins typically by the age of $16 .{ }^{2}$ Moreover, both males anc females are equally likely to smoke and white adolescents are more likely to smoke than theire African American or Hispanic counterparts. ${ }^{2}$,

Because smoking initiation and prevalence rates are still relatively high among teenagers an important area of research has been to focuso on the predictors of smoking onset in adoles $\frac{0}{\mathbb{D}}$ cents. It is known that smoking is a complexp behaviour and adolescents start to smoke for $\overrightarrow{0}$ many reasons. In a review of 27 prospective studies, ${ }^{4}$ several factors emerged as predictors of smoking onset. The four areas that provide. the most highly consistent indicators of smoking onset were (1) refusal skills; (2) smoking) intentions; (3) peer influences such as peeb smoking and approval; and (4) the offer anœ availability of cigarettes. Other consisten indicators include (5) attitudes and knowledge $e^{\circ}$ about smoking, and (6) peer and schoo $B$ bonding. Determinants of smoking onset mayt differ among boys and girls, and African Americans and whites, at least on some variables. $^{3-8}$

Conrad et al..$^{4}$ concluded that family (pares ticularly parental) smoking status played a les consistent role in predicting smoking onseP that the factors listed above. However, in one of the largest studies to date, Moss et al. ${ }^{3}$ found a strong, cross-sectional relationship between smoking and parental smoking status. For example, teenagers with parents who smoked or at least one older sibling who smoked were ${ }^{\circ}$ three times more likely to smoke than if no one in the household smoked.

Given that research has been fairly con $\frac{\mathbb{D}}{\mathbb{D}}$ sistent in identifying factors associated with? smoking initiation in teens, programmes have targeted these determinants with the aim of preventing smoking onset or decreasing the number of cigarettes smoked, or both. It general, smoking prevention programmes that have been developed and studied can be classified as educational, affective, and/or so-

\footnotetext{
cial influence approaches. A review of this area
} 
Table 1 Components of the programmes for teen smoking prevention of the American Lung Association and the Tobacco Institute

\begin{tabular}{|c|c|c|}
\hline $\begin{array}{l}\text { Programme } \\
\text { components }\end{array}$ & $\begin{array}{c}\text { American } \\
\text { Lung } \\
\text { Association }\end{array}$ & $\begin{array}{l}\text { Tobacco } \\
\text { Institute }\end{array}$ \\
\hline Stresses communication & Yes & Yes \\
\hline Suggests parents as role models & Yes & No \\
\hline $\begin{array}{l}\text { Discusses health consequences } \\
\text { of smoking }\end{array}$ & Yes & No \\
\hline Discusses peer pressure & Yes & Yes \\
\hline Discusses cost of smoking & Yes & No \\
\hline Discusses smoking as illegal act & No & Yes \\
\hline Discusses tips for quitting & Yes & No \\
\hline $\begin{array}{l}\text { Discusses responsible decision } \\
\text { making }\end{array}$ & Yes & Yes \\
\hline
\end{tabular}

indicates that the social influence approach is effective in preventing smoking onset. ${ }^{9,10}$ In addition, in a comparison between a social influence approach and an affective education approach, ${ }^{11}$ the former was more effective in preventing smoking onset than the latter.

Although several programmes exist that are designed for delivery in the school and are directed toward teens, we were interested in looking at the programme of the Tobacco Institute (TI). For comparison, the programme of the American Lung Association (ALA) was selected, given that the ALA is a non-profit organisation with an long history of smoking prevention and cessation. In addition, both organisations offer teen smoking prevention programmes designed for parents of teens. Both programmes are aimed at offering suggestions and strategies to parents in an effort to prevent smoking onset in children.

Table 1 summarises the major components of the TI's programme "Tobacco: Helping Youth Say No"12 and a pamphlet distributed by the ALA that addresses teenage smoking. ${ }^{13}$ Both programmes advocate enhancing parentchild communication and relations by keeping lines of communication open. In addition, both programmes address peer pressure and the role of the parent. Two areas where they seem to radically deviate, however, are peer pressure and the role of the parent. For example, the ALA suggests the use of a selfregulation model to reduce peer pressure to smoke, by stressing that "the child has the right and the ability to make their own decision about smoking" (p 10). Moreover, it is the posture of the ALA that parents should set an example of good health, not only in not smoking (or quitting) but in eating healthy meals and getting plenty of exercise (p 10). These strategies are designed to counter the findings that peer pressure and parental smoking status are predictors of smoking initiation. ${ }^{14,15}$

In contrast, the Tobacco Institute suggests that although adolescents are rebellious, parents may increase their influence with their children by "increasing trust, support, and understanding within the family" ( $p$ 4). Conrad and colleagues ${ }^{4}$ noted in their review that family bonding and approval were less indicative of smoking onset than peer and school bonding. In regards to parental smoking status, the Tobacco Institute seems to suggest a "do as I say, not as I do" approach. For example, the booklet states, "Whether or not you choose to drink or smoke, it is still your responsibility to discourage your children from smoking, until they are mature enough to make those adult decisions" (p 4).

As also noted in table 1 , both of these programmes advocate responsible decision making; however, they offer different strategies for accomplishing this goal. The ALA's approach to decision making and discussing smoking with teens is the following.

- Present the facts

- Listen to your teen's opinions

- Answer any questions

- Avoid moralising

- Encourage your child to make a wise decision about smoking.

The TI's programme outlines six steps for the teen to follow to make responsible decisions (p 6).

- Discuss the problem

- Gather more information

- List the alternatives

- Examine the consequences

- Consider feelings and values

- Choose the best possible course of action.

This is an effective problem solving/ decision making model; however, this procedure appears inconsistent with other suggestions offered in the booklet (such as "Smoking is not a choice for children because they do not have the maturity to make judgments that weigh all considerations" (p 7).

Several other components in each of these programmes differ. The ALA programme includes information on the health consequences of smoking, the costs of smoking, and tips for quitting. The literature supports the conclusion that information about the longterm and short-term health effects of smoking is effective in changing knowledge and attitudes. 9 ,10 In marked contrast to the ALA's approach, the TI's programme never mentions the health consequences of smoking or the benefits of quitting. Because virtually every health promotion/prevention programme provides information about the link between smoking and health, the lack of such information in the TI's programme is noteworthy. The TI does mention, however, in the section "Children Shouldn't Smoke" (p 9), that "Young people are aware of the claims that smoking presents risks to one's health."

Finally, another strategy offered in "Helping Youth Say No" is to provide the information that it is illegal to sell tobacco products to minors and in some places it is illegal for minors to buy tobacco products. Moss et al. ${ }^{3}$ noted that youth who smoked were twice as likely as other teens to engage in risk-taking behaviour. That is, smoking teens were more likely to have been in a fight, ridden a motorcycle or mini bike, or enjoyed risky activities "now and then". Given this information, it appears unlikely that pointing out the illegal nature of smoking would be an effective deterrent to teen smoking. Moreover, providing this information may potentially tempt youth to engage in the risky behaviour of purchasing and smoking cigarettes. 
In summary, although progress is being made in the area of smoking prevention among adolescents, many teens are still experimenting with cigarettes and the age of initiation is dropping, particularly among whites. In addition, both the TI and the ALA have suggestions on how to prevent smoking among adolescents. The content and specific strategies of these programmes, however, are markedly different.

Given that nearly one in five teenagers who are 16-18 years old are smoking at least 20 cigarettes a day, ${ }^{3}$ it is imperative that effective prevention strategies be identified. Who better to evaluate parental strategies than the target teens? Our study therefore had adolescents evaluate the components of the ALA's and TI's programmes, and rate how effective they perceive the strategies to be.

\section{Methods}

SUBJECTS

Participants were 172 students from six parochial schools in Memphis, Tennessee. All subjects were in the seventh grade. Subjects ranged in age from 11 to 16 (mean $=12.3$ years). The sample consisted of 89 girls and 83 boys, and $47 \%$ were reported to be Catholic (the census for the participating schools included $58 \%$ Catholic and $42 \%$ non-Catholic students). Sixty-two per cent of the children sampled were white, $33 \%$ were African American, and $5 \%$ were of another ethnic origin, indicating a high representation of the total census of Memphis (white: $67 \%$; African American : $29 \%$; other ethnic groups: $4 \%$. Of the students polled, $68 \%(\mathrm{n}=117)$ were classified as non-smokers and $32 \%(n=55)$ were smokers.

\section{MEASURES}

\section{Smoking history questionnaire}

The smoking history questionnaire asked about demographic background, the subject's smoking history and current smoking status.

\section{Strategy vignettes}

The components of both the ALA's and the TI's prevention programmes were presented in seven vignettes. The topics of the vignettes were peer pressure/enhanced communication, parents as role models, the health consequences of smoking, the cost of smoking, smoking as an illegal act, tips for quitting smoking, and responsible decision making. Peer pressure and communication were combined into one vignette due to the overlap of these topics. In cases where no information is given (such as the TI and the health consequences of smoking), information was extrapolated from other parts of the pamphlet. The participants were asked to rate the perceived effectiveness of both strategies individually on a six-point Likert scale, ranging from "not effective at all" to "very effective". After reading through both prevention techniques, subjects were required to choose between the two strategies as to which is the better smoking prevention technique. The vignettes are presented in the Appendix.

Instrument design and validation because the TI presents a similar format at the end of their ,booklet. The TI's scenarios $\overrightarrow{\vec{\rho}}$ however, are open-ended. By limiting theo participants to only two choices, these two음 programmes could be compared and the parti- $\frac{\overline{\bar{m}}}{\vec{\sigma}}$ cipants were forced into deciding between the $\frac{\Phi}{\propto}$ two strategies. Another factor considered in deciding on the vignette approach was that it $\vec{\circ}$ would be less threatening than asking students. directly about strategies their own parents may $\vec{\omega}$ or may not have attempted with them in regards to smoking behaviour and/or prevention.

This instrument was designed for ease of $\overrightarrow{0}$ reading and comprehension. Although parti-응 cipants were in the seventh grade, the in-strument was written at the fifth-grade edu-z cational level. Therefore, these vignettes would $\frac{0}{3}$ be appropriate for students with a variety of reading and comprehension skills. No dif- $\vec{\theta}$ ficulties were noted during the pilot administration to sixth graders.

The vignettes were then independently evaluated for content and ease of administration by the author and a clinical psychologistő with 10 years of expertise in smoking and $\stackrel{\mathbb{Q}}{\circ}$ smoking prevention. To establish construct $\vec{\circ}$ validity, 10 graduate students and faculty with expertise in behavioural medicine were asked to read both programme manuals and then? indicate which vignette is representative of the ALA versus the TI programme. The vignettes? were revised as needed.

To determine ease of administration and acceptability of the vignettes, the revised vignettes were administered to 22 sixth-grade $\underline{0}$ children. Test-retest reliability was deter-욱 mined by re-administration of the vignettes to these same students one week after the initial assessment. Two of the 22 children did not participate in the second administration due to 3 illness. Table 2 presents the percentage of $\frac{D}{0}$ endorsement agreement for each item from Time 1 to Time 2 as well as the percentage of 0 agreement for programme effectiveness scores. N Agreement was defined for programme effectiveness scores as scores within one Likertitem apart from Time 1 to Time 2 . As can be seen from the kappa values in table 2 , a high ट $_{\mathbb{\Phi}}$ degree of test-retest reliability was obtained.

\section{PROCEDURE}

Letters of consent were sent home with all $\stackrel{\mathbb{Q}}{\circ}$ potential participants with an addressed, stamped envelope. Participants for whom signed $ᄋ$ consent was received completed, during a음 group administration at their school: a demo-⿳亠丷厂 graphic questionnaire, a smoking history questionnaire, and a questionnaire composed of seven vignettes. Participants were asked to follow along as the instructions were read aloud. Two forms of the questionnaire were 
Table 2 Percentage of agreement (and kappa values) for programme endorsement and component effectiveness scores for the ALA and TI programmes from Administration One and Two

\begin{tabular}{|c|c|c|c|}
\hline \multirow[b]{2}{*}{ Programme components } & \multirow{2}{*}{$\begin{array}{l}\text { Programme } \\
\text { endorsement }\end{array}$} & \multicolumn{2}{|c|}{ Component effectiveness } \\
\hline & & $A L A$ & $T I$ \\
\hline $\begin{array}{l}\text { Peer pressure } \\
\text { Parents as role models } \\
\text { Health consequences of smoking } \\
\text { Cost of smoking } \\
\text { Smoking as illegal act } \\
\text { Tips for quitting } \\
\text { Responsible decision making }\end{array}$ & $\begin{array}{l}70(0.63) \\
100(1.0) \\
70(0.63) \\
65(0.57) \\
70(0.63) \\
85(0.78) \\
75(0.67)\end{array}$ & $\begin{array}{l}75(0.67) \\
95(0.91) \\
80(0.70) \\
70(0.63) \\
75(0.67) \\
85(0.78) \\
80(0.70)\end{array}$ & $\begin{array}{l}75(0.67) \\
80(0.70) \\
70(0.63) \\
70(0.63) \\
90(0.86) \\
85(0.78) \\
80(0.70)\end{array}$ \\
\hline
\end{tabular}

$\mathrm{ALA}=$ American Lung Association; $\mathrm{TI}=$ Tobacco Institute

used to counterbalance the order of vignette presentation as well as the order of the ALA and TI strategies. Upon completion, questionnaires were checked for completeness and students were debriefed.

\section{DESIGN AND ANALYSIS}

This study was conceptualised as a withinsubjects design. The dependent variables, within-subjects factors, were mean effectiveness scores for each programme component and the percentage of endorsement for both the ALA and the TI programmes. The independent variables were sex, race, and the smoking status of the rater. Participants were originally classified as smokers, experimental smokers, and never-smokers. Criteria for these categories were the following.

- Smokers - participants who smoked at least one cigarette per week

- Experimental smokers-participants who have ever smoked a cigarette, even a puff

- Never-smokers - subjects who have never had a cigarette of a puff of a cigarette.

Because of zero cells for smoking status categories noted during sex and race analyses, the smoker and experimental smoker categories were collapsed. In addition, programme components (peer pressure/enhanced communication, etc.) were analysed for gender, race, and smoking status effects. As the first study to analyse the components of these two programmes with their target population, univariate tests were used instead of multivariate analysis of variance to identify specific differences as a function of programme, sex,

Table 3 Mean effectiveness scores (and standard deviations) and the percentage of programme endorsement for all programme components

\begin{tabular}{lcccccc}
\hline & \multicolumn{3}{c}{ Component effectiveness } & & \multicolumn{2}{c}{$\begin{array}{c}\text { Programme } \\
\text { endorsement }\end{array}$} \\
\cline { 2 - 3 } \cline { 6 - 7 } Programme components & $A L A$ & $T I$ & $t$ & & ALA & TI \\
\hline Peer pressure & $2.92(1.44)$ & $2.52(1.32)$ & $-2.70^{\star}$ & & 59.9 & 40.1 \\
Parents as role models & $3.70(1.26)$ & $1.49(1.39)$ & $-14.35^{\star}$ & 84.9 & 15.1 \\
$\begin{array}{l}\text { Health consequences } \\
\text { of smoking }\end{array}$ & $3.44(1.42)$ & $1.42(1.65)$ & $-11.26^{\star}$ & 80.2 & 19.8 \\
$\begin{array}{l}\text { Cost of smoking } \\
\text { Smoking as illegal act }\end{array}$ & $2.74(1.45)$ & $1.82(1.63)$ & $-5.29^{\star}$ & & 70.9 & 29.1 \\
Tips for quitting & $1.93(1.55)$ & $2.88(1.29)$ & $+5.72^{\star}$ & & 34.3 & 65.7 \\
$\begin{array}{l}\text { Responsible decision } \\
\text { making }\end{array}$ & $3.41(1.47)$ & $1.76(1.60)$ & $-9.82^{\star}$ & 74.4 & 25.6 \\
Overall & $3.44(1.55)$ & $2.59(1.34)$ & $-5.74^{\star}$ & 73.8 & 26.2 \\
\hline
\end{tabular}

$\star p<0.01$.

$\mathrm{ALA}=$ American Lung Association; $\mathrm{TI}=$ Tobacco Institute. race, and smoking status. To address the issue of multiple analyses, however, an alpha level of 0.01 was adopted.

\section{Results}

\section{COMPONENT EFFECTIVENESS}

To evaluate programme components (peer pressure/enhanced communication, parents as role models, the health consequences of smoking, the cost of smoking, smoking as an illegal act, tips for quitting smoking, and responsible decision making), paired $t$ tests were performed on the effectiveness scores for each programme component and mean programme scores. Table 3 displays the mean effectiveness scores, standard deviations, and $t$ values for all programme components. All programme components for the ALA programme were found to be rated significantly more effective than the TI programme with the exception of smoking as an illegal act (all probability values less than 0.01 ). This TI component was rated significantly more effective for preventing cigarette smoking than the ALA's counter component.

To assess programme components by sex, race, and smoking status, perceived effectiveness scores were also analysed using a repeated measures analysis of variance design with the within-subjects factor of programme. No order effects were indicated; therefore, all analyses were collapsed across form type. A significant sex-by-programme interaction was noted for peer pressure $(F(1,155)=6.28, \mathrm{p}>$ $0.01)$, tips for quitting $(F(1,155)=9.07, \mathrm{p}<$ $0.01)$, and decision making $(F(1,155)=8.66$, $\mathrm{p}<0.01$ ). For all three programme components, girls gave mean scores to the ALA's approach (peer pressure $=3.18$, tips for quitting $=3.90$, decision making $=3.72$ ) that were significantly higher than those given by the boys (peer pressure $=2.47$, tips for quitting $=$ 2.08 , decision making $=2.60$ ). In the case of both "tips" and "decision making", Tukey follow ups indicated that girls rated the ALA approach (mean scores of 3.90 and 3.71, respectively) significantly higher than the TI approach (1.46 and 2.58, respectively).

\section{PROGRAMME ENDORSEMENT}

The Wald $\chi^{2}$ test was used to assess the percentage of programme endorsement (ALA vs TI) for all programme components (table 3 ). This analysis determined if subjects had a programme preference when having to choose one programme over another. For total programme endorsement, significantly more participants choose the ALA programme over that of the TI (Wald $\chi^{2}(1, \mathrm{n}=172)=9.49, \mathrm{p}<$ $0.01)$. In addition, a higher percentage of whites endorsed the ALA programme compared with other ethnic groups (Wald $\chi^{2}(1$, $\mathrm{n}=172)=6.81, \mathrm{p}>0.01$ )

A significant gender difference was noted for "decision making" (Wald $\chi^{2}(1, \mathrm{n}=172)=$ $7.96, p<0.01$ ), with a higher percentage of girls than boys endorsing the ALA approach. Moreover, a higher percentage of whites $(n=97)$ endorsed the ALA approach than 
did African Americans $(n=43)$ for the "parents as role models" component (Wald $\chi^{2}$ $(1, \mathrm{n}=172)=7.29, \mathrm{p}<0.01)$.

\section{Discussion}

The results of our study indicated that all components of the ALA programme were rated as more effective in preventing teen smoking than the TI programme, with the exception of smoking as an illegal act. The participants endorsed the TI's notion of advising teens that the purchase and use of tobacco products are illegal for minors. This component is one of the most questionable, however, because of the literature on adolescence and risk-taking behaviour. Adolescents who use tobacco products are also more likely to engage in other risk-taking behaviours such as carrying weapons, fighting, high-risk sexual behaviour, and use of alcohol and other drugs. ${ }^{2,4,14,16}$ Perhaps the endorsement of this strategy is a function of age; that is, as these children age, perhaps they would be less likely to endorse the advising of teens that tobacco use is illegal for minors as an effective prevention strategy. Future studies should reexamine these findings, in particular in older children and adolescents.

Programme component analyses revealed that girls rated the ALA's approach to peer pressure, quitting tips, and decision making as more effective than did boys. In addition, girls rated the ALA programme higher on tips for quitting and decision making than the TI programme. These findings, along with the findings that whites were more likely than African Americans to endorse the ALA's programme overall and the notion of parents as role models, suggest that smoking prevention strategies should be designed for target populations. Other studies ${ }^{8,17,18}$ have noted that parental smoking status appears to be a more significant predictor of smoking in white children than in African Americans. Other studies have noted race effects in regards to smoking predictors. For example, Sussman et $a l .{ }^{8}$ and Landrine et al. ${ }^{19}$ noted that risk taking was a reliable predictor for African Americans, but not for whites. Future studies should investigate population-specific strategies (for example, in males, females, whites, African Americans) with longitudinal designs that cover the pre-adolescent and adolescent years.

Although there are a number of positive aspects to this study (use of a racially heterogeneous sample, and the use of adolescents), there are also limitations. The study was conducted in one city, consisting of an urban and suburban population. Data collected in different regions with different ethnic populations may yield different results. In addition, although the sample was nearly equally split between Catholics and non-Catholics, the information was collected from children enrolled in parochial schools. Caution should be used in generalising these findings to other samples.

In summary, this study represents an appraisal of the Tobacco Institute's programme relative to the American Lung Association's programme by those whom these programmes are ultimately intended to influence. The consistency and magnitude of the low pre- $-\overrightarrow{0}$ ference for the TI programme suggest that perhaps little programme or outcome evalu-을 ation was undertaken with the TI programme. The low perceived effectiveness of the TI programme is unfortunate given its wide $\stackrel{\overrightarrow{9}}{\stackrel{7}{?}}$ dissemination. The Tobacco Institute solicits school participation in the programme and흠 offers these materials free of charge, ${ }^{20,21}$ where- $\frac{\bar{c}}{2}$ as the ALA supplies information upon re- $\mathbb{Q}$ quest. ${ }^{22}$ Given the data presented here showing that potential recipients of the product rate it $\rightarrow$ as relatively ineffective, the TI programme? should be further investigated before being $\vec{\omega}$ recommended for use as a smoking prevention tool for adolescents.

This study was supported by NIH Research Grant HL-50723, funded by the National Heart, Lung, and Blood Institute; National Institutes of Health. 1 American Cancer Society. Cancer facts and figures. Atlanta, $\frac{\gtrless}{2}$

2 US Department of Health and Human Services. Preventing tobacco use among young people. A report of the Surgeon $\overrightarrow{0}$ General. Atlanta, Georgia: Public Health Service, Cen- 8 ters for Disease Control and Prevention, Office on Smoking and Health, 1994. (US Government Printing Office No S/N 017-001-00491-0.)

3 Moss AJ, Allen KF, Giovino GA, Mills SL. Recent trends in adolescent smoking, smoking uptake correlates, and expectations about the future. Advance data from vital and $\overline{\mathrm{O}}$ health statistics; no. 221 . Hyattsville, Maryland: National Center for Health Statistics, 1992.

4 Conrad KM, Flay BR, Hill D. Why children start smoking cigarettes: Predictors of onset. Br $\mathscr{F}$ Addict 1992; 87: $\overrightarrow{\bar{D}}$ 1711-24.

5 Camp DE, Klesges RC, Relyea G. The relationship between body weight concerns and adolescent smoking. Health Psychol 1993; 12: 24-32.

6 Headen SW, Bauman KE, Deane GD, Koch GG. Are the correlates of cigarette smoking initiation different in African-American and white adolescents? Am $\mathcal{F}$ Public Health $1991 ; 7: 854-7$.

7 Farwell AD, Danish SJ. Peer drug associations and emotional restraint: Causes or consequences of ado-O lescents' drug use? f Consult Clin Psychol 1993; 61:O 327-34.

8 Sussman S, Dent CW, Flay BR, Hansen WB, Johnson CA. Psychosocial predictors of cigarette smoking onset by White, Black, Hispanic, and Asian adolescents in south- $\overline{7}$ ern California. $M M W R$ 1987; 36: (suppl) 11-16S.

9 Flay BR, d'Avernas JR, Best JA, Kersell MW, Ryan KB. Cigarette smoking: Why young people do it and ways of preventing it. In : McGrath PJ, Firestone P, eds. Pediatric and adolescent behavioral medicine: Issues in treatment. 음

10 Flay BR. Social psychological approaches to smoking $D$ prevention: review and recommendations. Adv Health Promotion 1987; 2: 121-80.

11 Hansen WB, Johnson CA, Flay BR, et al. Affective and N social influences and approaches to the prevention of multiple substance abuse among seventh grade students: N results from project SMART. Prev Med 1988; 17: N 135-54.

12 Tobacco Institute. Tobacco: Helping youth say no. Washington, DC: Tobacco Institute, 1987.

13 American Lung Association. Teenage smoking is a majoro health problem. South Deerfield, Massachusetts: Chan- $\frac{C}{\Phi}$ ning L Bete Co. Inc., 1991.

14 Chassin L, Presson CC, Montello D, Sherman SJ, McGrew? $\mathrm{J}$. Changes in peer and parent influence during ado- $\square$ lescence: Longitudinal versus cross-sectional pers- $\overline{0}$ pectives nonsmoking initiation. Dev Psychol 1986; $22: \frac{\text { (D) }}{\text { ( }}$ pectives

15 Covington MV, Omelich CL. I can resist anything but temptation: Adolescent expectations for smoking cigarettes. F Appl Soc Psychol 1988; 18: 203-27.

16 Scheier LM, Newcomb MD. Differentiation of early adolescent predictors of drug use versus abuse: Å developmental risk-factor model. F Substance Abuse 1991 : 3: $277-99$.

17 Botvin GJ, Baker E, Goldberg CJ, Dusenbury L, Botvin으 EM. Correlates and predictors of smoking among black adolescents. Addict Behav 1992; 17: 97-103.

18 Croft JB, Mac D, Hunter S, Webber LS, Watson RB, Berenson GS. Cigarette smoking and behavioral distinctions between experimental nonadopters and adopters in children and adolescents: A consideration of transitional smoking experience. Prev Med 1985; 14: 109-22. 
19 Landrine H, Richardson JL, Klonoff EA, Flay B. Cultural diversity in the predictors of adolescent smoking: The relative influence of peers. f Behav Med 1994; 17: 331-46.

20 Tobacco Institute. The Tobacco Institute: Scope and activities. Washington, DC: Tobacco Institute, undated.
21 DiFranza JR, McAfee T. The Tobacco Institute: Helping youth say "yes" to tobacco. f Fam Pract 1992; 6: 694-6. 22 American Lung Association of Tennessee, Inc. The case for lung health in Tennessee...lung disease can strike anyone. Memphis, Tennessee: American Lung Association of Tennessee, Inc., undated.

\section{Appendix}

The seven strategy vignettes used in this study are presented below. The three questions and the accompanying Likert scales shown below for the first vignette were used for the other vignettes, but are omitted below to conserve space. In the study, all vignettes were presented on a separate page and without topic headings.

\section{PEER PRESSURE/ENHANCED COMMUNICATION}

Kelly's parents are concerned about how Kelly's friends may influence her. They are afraid that because some of Kelly's friends smoke, she may start. Kelly's parents have talked to some of their friends about what to say to Kelly. They have received different advice depending on who they talk to.

A) Some people say: "Communicate more and be more interested in Kelly's activities. This will add to your influence by increasing the trust, support, and understanding in the family." It was also suggested that they practise with Kelly ways to say no to smoking - for example, "A cigarette? No thanks, my parents would ground me for a month if they caught me smoking".

B) Other people agreed that : "It is important to communicate with Kelly and let her know that you care about her." But they differed from the people in response $A$ in that they believe that Kelly's parents should encourage her to think for herself and remind her that she doesn't need to give in to peer pressure."

How well do you think $A$ would be in stopping teens from smoking cigarettes?

\begin{tabular}{lrllll}
0 & 1 & 2 & 3 & 4 & 5 \\
\hline $\begin{array}{l}\text { Not effect }- \\
\text { ive at all }\end{array}$ & & & & $\begin{array}{l}\text { Very } \\
\text { effective }\end{array}$
\end{tabular}

How well do you think $B$ would be in stopping teens from smoking cigarettes?

\begin{tabular}{lrllll}
0 & 1 & 2 & 3 & 4 & 5 \\
\hline $\begin{array}{l}\text { Not effect- } \\
\text { ive at all }\end{array}$ & & & & $\begin{array}{l}\text { Very } \\
\text { effective }\end{array}$
\end{tabular}

If someone asked you to help make a stopsmoking book for teens, which strategy would you use? (Circle one) A or B

\section{PARENTS AS ROLE MODELS}

Keisha's parents don't want her to smoke, but both her parents smoke cigarettes. Keisha's parents have talked to some of their friends about what to say to Keisha. They have received different advice depending on who they talk to.

A) Some people say: "It is not important if the parent smokes. After all, parents are adults and are mature enough to make decisions about smoking. Children should not smoke because they are not mature enough to make this adult decision. Besides, children should do what their parents say, and not what they do."

B) Other people say: "If Keisha's parents do not want her to smoke, then they should set a good example by not smoking and doing other healthful things like eating a balanced diet and exercising. Keisha's parents can not expect Keisha not to smoke if they do."

\section{HEALTH CONSEQUENCES OF SMOKING}

Jeff's parents don't want him to smoke cigarettes. Jeff's parents have talked to some of their friends about what to say to Jeff about the health consequences of smoking. They have received different advice depending on who they talk to.

A) Some people say: "It is important to tell kids that smoking is addictive and bad for their health. Kids need to know that smoking causes cancer, and heart and lung disease."

B) Other people say: "It is not helpful to tell kids how smoking would affect their health. Kids don't care about things like that, they think nothing can hurt them. Besides, who knows if the claims that smoking present risks to one's health are true."

\section{COST OF SMOKING}

Gail's parents believe that Gail is considering smoking. Gail's parents have talked to some of their friends about what to say to Gail. They have received different advice depending on who they talk to.

A) Some people say: "Remind Gail how expensive it is to take up smoking. Point out that smoking a pack a day would cost approximately $\$ 600$ a year. Ask her to think of other things she might want to buy with that money."

B) Other people say: "It doesn't make any sense to talk about how much smoking costs."

\section{SMOKING AS AN ILLEGAL ACT}

Jamal is a teen who is considering smoking. Jamal's parents have talked to some of their friends about what to say to Jamal. They have received different advice depending on who they talk to.

A) Some people say: "Jamal's parents should tell him that it is illegal for tobacco products to be sold to minors and in some places, illegal for minors to buy tobacco products. They should also tell him that he could get into trouble or get someone else in trouble if he tried to buy tobacco products."

B) Other people say: "Telling Jamal that smoking is illegal is silly. Telling him it's illegal and that he may get into trouble won't 
help, sometimes kids like to do risky things. Besides, if you tell teens not to do something, something that only adults are suppose to do, sometimes they will want to try it."

\section{TIPS ON QUITTING}

Chris is a teen who may be smoking. Chris's parents have talked to some of their friends about what to say to Chris. They have received different advice depending on who they talk to.

A) Some people say: "Chris' parents should try to help him to quit by offering some suggestions, such as:

- Make a firm decision to quit

- Prepare yourself - make of list of reasons why you want to quit, chose a method for quitting, select a quit date

- Quit - get rid of all smoking materials

- Reinforce your decision-try substitutes, re-read your list of reasons, spend time in places where smoking is not allowed, make plans to spend the money you save, and celebrate your anniversaries."

B) Other people say: "It doesn't make any sense to give kids tips on quitting. Because they should not be allowed to smoke to begin with. Kids cannot make the decision to smoke until they are adults."

\section{RESPONSIBLE DECISION MAKING}

Tyrone's parents realise that choosing to smoke or not is a tough decision. They discuss with him ways to go about making decisions -1

A) Tyrone: "I want to start smoking."

Parents: "There are some things you need t $\mathscr{Q}$ know before you make that decision. First, yot know, smoking is illegal for minors. More importantly, it is an adult decision. You ca丐 decide when you are an adult, not now. If yot

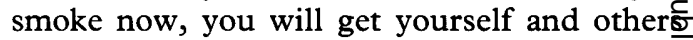
(those who sell you cigarettes) in trouble. Whasp do you think about that?"

Tyrone: "I don't like this, but OK."

B)Tyrone: "I want to start smoking."

Parents: "There are some things you need $\vec{P}$ to know before you make that decision. First $\overrightarrow{e v}$ smoking is addictive. Second, smoking harms you immediately as well as in the future. I causes heart and lung disease, as well as cancerIs there anything else I can tell you aboud smoking?

Tyrone: "Do you think smoking is wrong?"

Parents: "It is certainly bad for you and we care for you. But it is up to you to make youf own decision about smoking. We know yoư will make a wise choice."

\section{2nd Annual \\ TOBACCO USE PREVENTION SUMMER INSTITUTE \\ July 8 - 12, 1996 \\ St. Louis, Missouri}

The Center for Health Promotion and Disease Prevention at The University of North Carolina, in conjunctiog with the Centers for Disease Control and Prevention's Office on Smoking and Health, will sponsor the Secong Annual Tobacco Use Prevention Summer Institute from July 8 - 12, 1996, in St. Louis, Missouri. Leading. faculty from across the United States will conduct eight comprehensive courses:

\section{Managing State/Local \\ Programs \\ Tobacco Advertising}

Media and Policy Advocacy

Coalition Building
Environmental Tobacco Smoke

Tobacco Pricing
Youth and Tobacco Epidemiology and Evaluation

The Summer Institute will offer comprehensive courses in tobacco use prevention and reduction, balancing backgrount research, theory, and practical experience. Modeled after other successful leadership institutes based at academ institutions, the Institute emphasizes broadening the knowledge and skills of professionals actively involved in state and local tobacco control programs, particularly for programs designed to prevent youth tobacco use.

A COMPlete BROCHURE, INCLUDING APPLICATION FORM, WILl BE AVAILABLE IN LATE MARCH.

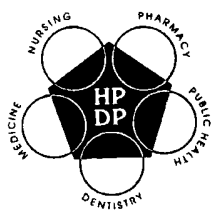

For Further Information, Contact:

Ginger Morgan, Project Manager

The University of North Carolina

Center for Health Promotion and Disease Prevention

Tobacco Use Prevention Training Program

Manning Drive, CB \#7595, Chapel Hill, NC 27599-7595

Phone: +1 919 966-5653 Fax +1 919 966-0973

E-Mail: ginger_morgan@unc.edu 